\title{
Evaluation Quality of Guava Juice Fortified with Probiotic
}

\author{
Heba Y. Nasef \\ Nutri. \& Food Sci. Dept., Faculty of Home Economics, Helwan University, Egypt \\ E-mail:hobanasif91@yahoo.com
}

\author{
Ahmed A. Farrag \\ Nutri. \& Food Sci. Dept., Faculty of Home Economics, Helwan University, Egypt \\ E-mail:Aelatawy@yahoo.com \\ Eman F. Mohamed \\ Nutri. \& Food Sci. Dept., Faculty of Home Economics, Helwan University, Egypt \\ E-mail:eeman.ali3000@gmail.com
}

\begin{abstract}
Abd El-Aziz N. Shehata
Dairy Science Dept., Food Industry and Nutrition Research Division, National Research Centre, 33 El Buhouth St., 12622 Dokki, Giza, Egypt. E-mail: zanadir666@gmail.com.

\section{G.A. Ibrahim}

Dairy Science Dept., Food Industry and Nutrition Research Division, National Research Centre, 33 El Buhouth St., 12622 Dokki, Giza, Egypt. E-mail: gamalwahab2015@gmail.com
\end{abstract}

Received: 10 May 2020/Accepted 20 July 2020 / Publication date: 25 July 2020

\begin{abstract}
Recently, new nutritional trends, consumers' concern for healthy lifestyle, growing numbers of vegetarians, and vegans in developed and developing countries, as well as the low cost of obtaining plant materials also contribute to greater demand for nondairy-fermented products (probiotic fruit juice) so. This study was carried out to evaluate the functional properties of probiotic (Lb. rhamnosus and $L b$. acidophilus $2 \%$ ), prebiotic (inulin- $2 \%$ ) and synbiotic on quality attributes of guava juice during storage periods (1, 2 and 3 weeks) at refrigerator temp $\left(2-6{ }^{\circ} \mathrm{C}\right)$. Microbiological, chemical, physical analyses and sensory properties were investigated. Four treatments were studied. Fresh guava juice was taken immediately after processing, $\mathrm{T}_{5}$ Guava juice $+L b$. acidophilus + inulin, $\mathrm{T}_{6}$ Guava juice $+L b$. acidophilus without inulin, $\mathrm{T}_{7}$ Guava juice $+L b$. rhamnosus + inulin and $\mathrm{T}_{8}$ Guava juice $+L b$. rhamnosus without inulin, in addition of control sample (guava juice only). Objective and sensory evaluations were carried out to indicate the acceptability of the final products. According to sensory evaluation, after 3 weeks of storage there were, no significant differences $(p<0.05)$ in all sensory characteristics of guava juice fortified with probiotic in all treatments as compared to control sample. Total sugars (reducing sugars, non-reducing sugars), Vitamin $\mathrm{C}$, PH, acidity, total soluble solid, viscosity and color of the products were evaluated. All treatments of guava samples achieved a mean viable count of at least $10^{7} \mathrm{CFU} / \mathrm{ml}$ during storage period. It could be concluded that the probiotic bacteria grew well in all treatments and were capable of surviving and maintaining high viability and enhancing functional properties in the all treatments during storage period without any changes in quality attributes of fruit juices. Therefore, this study indicated a potential for probiotic fruit juices as a valid alternative to dairy based probiotic products. High numerous health benefits of inulin, when combined with the health benefits of probiotic bacteria, could lead to the development of commercial beverages with high health and nutritional values. So food industries should be encourage use probiotic and prebiotic in several products to achieve health benefits of them.
\end{abstract}

Keywords: functional foods, fortification, probiotic, prebiotic, synbiotic, inulin, Lb. rhamnosus, Lb. acidophilus, fruit juices, guava.

Corresponding Author: Ahmed A. Farrag, Nutri. \& Food Sci. Dept., Faculty of Home Economics, Helwan University, Egypt. E-mail:Aelatawy@yahoo.com 


\section{Introduction}

Nowadays, functional foods are receiving much interest from consumers across the world because they have beneficial actions in the body such as reduction of disorder risks, increasing some enzymatic activities and effect on many targets in the same time (Guimaraes et al., 2018). In addition to the traditional nutritional effects, "Functional foods" exert beneficial health effects on body. Wellrecognized examples of functional foods are those containing bioactive compounds like dietary fibers, oligosaccharides, vitamins, minerals and active "friendly" bacteria, called probiotics that promote the equilibrium of intestinal micro flora (Shah and Prajapati, 2013).

Fortification is achieved by adding one or more essential nutrients to foodstuff, usually to prevent or correct deficiencies and enhance the nutritional value (Tomic et al., 2017). Fortifying fruit juice products with fiber is of increasing interest in creating functional foods with health benefits and improving their functionality (Gahruie et al., 2015).

The food products containing probiotic substances have been assessed to represent $60-70 \%$ of the total functional foods market (Kareb and Aïder, 2018). A probiotic has been defined as living 'live microorganism which when administered in adequate amounts confers a health benefit on the host' (FAO/WHO, 2002). Probiotics should not only survive in the food product but should also be able to reach the small intestine alive. Most common probiotics belong to the heterogeneous group of lactic acid bacteria (e.g., Lactobacillus, Enterococcus) and genus L. rhamnosus is an extensively studied strain with well-documented probiotic properties (Saad et al., 2013).

Lactobacillus rhamnosus was first used in the studies at 1990 and was found beneficial to children's health. Some of the main traits of Lactobacillus rhamnosus are being indigenous to human intestinal flora, resistance to low $\mathrm{pH}$ values and adherence to gastrointestinal track Canbulat and Ozcan, (2007). Lactobacillus acidophilus was first isolated from children's by Ernst Moro in 1900 and in 1970 it was officially acknowledged as L.acidophilus by Hansen and Mocquat. This term means lactic acid bacteria which can show growth in an acidic environment (Ozden, 2008). Lactobacillus acidophilus has an antimicrobial effect due to the formation of organic acids (lactic acid, acetic acid, etc.) L. acidophilus is resistant to bile acid and has a strong antibiotic effect on fecal E. coli strains and other intestinal pathogens (Ahmed et al., 2010).

To confer a health benefit to the host, a minimum therapeutic level $\left(10^{6}-10^{7} \mathrm{cfu} / \mathrm{g}\right.$ or $\mathrm{ml}$ of carrier food product) capable of manipulating biological function must be maintained throughout the shelf life of the product (Bansal et al., 2016). There are two more essential terms to know, Prebiotics act as the fuel for probiotics and are found naturally in a variety of foods such as leeks, onions, garlic, and aspragus (Newgent, 2013). Generally, the most common prebiotics are soluble fibers such as inulin (Fazilaha et al., 2018). Inulin is more preferable compared to other prebiotics such as fructooligosaccharides (FOS) due to some specification such as solubility in water, pleasant sweetness and absence of any odor and color (Ferrao et al., 2016).

A synbiotic can be defined as the supplement which contains both prebiotic and probiotic factors that work together and improve the "friendly flora" of the human intestine (Thakur, 2016).

Fruit juices contain high amounts of sugars which could encourage probiotic growth and could easily be monitored using a refract meter. Fruit and vegetable juices are considered as an ideal carrier for the delivery of probiotics as they contain notable levels of vitamins and antioxidants, considered suitable for lactose intolerant people (Vodnar et al., 2019). Guava fruit is widely cultivated in tropical and subtropical regions and is becoming increasingly popular worldwide. In general, guava fruit has pleasant aroma notes, such as fruity and sweet (Bashir and Abu-Goukh, 2003). Guava is a tropical fruit characterized by a low content of fats and proteins, and high vitamin $\mathrm{C}$ content and crude fiber levels, as well as an extraordinary content of carotenoids, especially lycopene. In addition to its nutritious profile, guava presents notable sensory properties (Osorio et al., 2011).

The increase in the number of vegetarian consumers has increased the demand for nondairy probiotic products. Lactose intolerance, allergies to milk protein, and high cholesterol are other major drawbacks related to fermented dairy products (Martins et al., 2013). Finally, the market for nondairyfermented food for example (probiotic fruit juices) has developed for health-related and economic reasons (Panghal et al., 2018). The objective of the present study was develop a new functional fruit juice fortified with inulin and probiotic starter (Lactobacillus acidophilus, Lb. rhamnosus) individually and synbiotic, improve the viability of different strainin guava juice when combined with (2\%) long 
chain inulin fiber during storage period, evaluate the sensory attributes as well as on the overall acceptance and overall quality of the final product (guava juice).

\section{Materials and Methods}

\section{Materials}

1.1. Guava Fruits were obtained from local markets, Cairo, Egypt.

1.2. Probiotic strains (Lactobacillus rhamnosus NRRL B-442, Lactobacillus acidophilus, and Bifidobacterium breve ATCC 17500) were obtained from Dairy Microbiological Lab., Dairy Science Dep., Food Industries and Nutrition Research Division, National Research Center, Dokki, Giza, Egypt.

\subsection{Chemicals}

Inulin was purchased from SEARLE Company (CHADWELL HEATH ESSEX), England; MRS was supplemented by SRL Co., India; Malt Extract Agar was provided by Oxoid, England; MaCconkey broth was provided from LAB m, UK. All microbiological media were recommended by APHA, (1976) and FDA, (2002), and further prepared according to the proper procedures of manufacturers. Chemicals used for proximal determination was purchased from Chemicals Co., in Egypt.

\section{Methods}

Flow chart for preparation of probiotic fruit juice

Preparation of raw materials (guava) $\rightarrow$ washed $\rightarrow$ skins and seeds removed $\rightarrow$ ground

pasteurization at $80^{\circ} \mathrm{C}$ for 15 min and immediately cold at $4^{\circ} \mathrm{C}$<smiles>[AlH2]</smiles>

To prevent contamination (critical point)

$$
\downarrow
$$

Juice mixture with inulin extraction $2 \%+$ strain of probiotic

Mixture kept at refrigerator temp $\left(2-6^{\circ} \mathrm{C}\right)$.

\subsection{Preparation of raw materials:}

Guava was washed in tap water and Guava puree was prepared from fresh fully ripe guava fruit according to the method described by Boyle et al. (1957), then pasteurized at $80^{\circ} \mathrm{C}$ for $15 \mathrm{~min}$ and immediately cold at $4^{\circ} \mathrm{C}$ (Vieira and Silva, 2014).

\subsection{Probiotic Culture Preparation:}

All strain of Lactobacillus rhamnosus and lactobacillus acidophilus which suspended in MRS broth was inoculated $(2 \% \mathrm{w} / \mathrm{v})$ into skimmed milk and anaerobically incubated at $37^{\circ} \mathrm{C}$ for $24 \mathrm{~h}$. After the formation of good coagulate that contained $10^{6} \mathrm{cfu} / \mathrm{g}$, the cultures were transferred to a refrigerator at $4{ }^{\circ} \mathrm{C}$, and became ready for use.

\section{The overall treatments of Guava samples preparation}

Control sample (370 ml ) Guava juice only

(T) Guava juice $(370 \mathrm{ml})+2 \%$ Lactobacillus acidophilus $(7.4 \mathrm{ml})+$ inulin $2 \%(17 \mathrm{~g})$.

(T) Guava juice $(370 \mathrm{ml})+2 \%$ Lactobacillus acidophilus $(7.4 \mathrm{ml})$ without inulin.

( $\left.\mathbf{T}_{7}\right)$ Guava juice $(370 \mathrm{ml})+2 \%$ Lactobacillus rhamnosus $(7.4 \mathrm{ml})+$ inulin $2 \%(17 \mathrm{~g})$.

(T) Guava juice $(370 \mathrm{ml})+2 \%$ Lactobacillus rhamnosus $(7.4 \mathrm{ml})$ without inulin.

\section{Microbiological Analysis}

The microbiological analysis of different samples of Guava juice under this investigation was carried out including the determination of total bacterial count (TBC), yeasts and molds counts according to the methods recommended in the American Public Health Association (1976).

\subsection{Total bacterial count}

The total bacterial count was performed using the plate count agar medium as recommended by (APHA, 1976 and FDA, 2002). 


\subsection{Enumeration of Lactobacilli}

Enumeration of Lactobacillus spp. from all fruit juice samples was carried out during storage period ( 0 times, 1 week, 2 week, and 3 week). Serial dilutions and subsequent plating were used to determine microbial counts of Lactobacillus spp.

\subsection{Enumeration of Coliforms group}

Coliforms counts were enumerated on MacConkey broth (WHO, 1963). The method was described by El-Hadedy and Abu El-Nour, (2012).

\subsection{Enumeration of molds and yeasts:-}

Molds and yeasts were determined using malt extract agar Galloway and Burgess, (1952).

\section{Objective evaluation includes}

4.1. Chemical Examination

\subsubsection{Determination of total sugars}

The total, reducing and non-reducing sugars in fruit juices under investigation were determined by the official Lane-Eynone titrimetric method as described in AOAC (2005).

\subsubsection{Determination of ascorbic acid}

Ascorbic acid content was estimated according to AOAC (2005) using 2, 6 dichlorophenolindophenols by titration method. Result was expressed as $\mathrm{mg}$ ascorbic acid per $100 \mathrm{ml}$ samples.

\subsection{Physico chemical analysis}

\subsubsection{Determination of $\mathbf{P H}$ values}

The PH value of all fruit juice samples were measured separately by digital PH meter (model 3505- JENWAY - UK) after (0 times, 1 week, 2 week, 3 week) at $25^{\circ} \mathrm{C}$ as described in AOAC (2005).

\subsubsection{Determination of total titratable acidity}

Total titratable acidity was measured as mentioned in the official method of the AOAC, (2005). It was expressed as citric acid or malic acid using sodium hydroxide N/10 and phynol phythaline as indictor to get $\mathrm{pH}$.

\subsubsection{Determination of total soluble solids}

Total soluble solids (T.S.S) were determined by using a refractometer, Carl Ziess, Jena (Germany) at $20^{\circ} \mathrm{C}$. A correction was made for different temperatures and the results were reported as ${ }^{\circ} \mathrm{Brix}$ at $20^{\circ} \mathrm{C}$.according to the method described by the AOAC (2005).

\subsection{Physical properties}

\subsubsection{Viscosity}

Viscosity was measured in fruit juice samples at $7^{\circ} \mathrm{C}$ using a Brookfield digital viscosity (Model DV- II+VISCOMETER, Spindle-00). The speed was set from 3 to $50 \mathrm{rpm}$. Three reading, 30s apart, were recorded for each sample.

\subsubsection{Color analysis}

The color of Mango juice samples after cold storage period (7days, 2 weeks and 3 weeks) was measured according to Hunter (1975), spectro-colorimeter (Tristimulus Color Machine) with CIE lab color scale (Hunter, Lab Scan XE, Germany) calibrated with a while standard tile of Hunter Lab color standard (LXNO. 16379): $X=77.26, Y=81.94$ and $Z=88.14\left(L^{*}=92.71 ; a^{*}=-0.89 ; b^{*}=-0.18\right)$ where $\mathrm{L}^{*}=$ Lightness, $\mathrm{a}^{*}=$ redness, $\mathrm{b}^{*}=$ yellowness), using Hunter-scot field's equation( Hunter,1975) as follows:

$$
\Delta E=\left(\Delta a^{2}+\Delta b^{2}+\Delta L^{2}\right)^{1 / 2}
$$

Where $\mathrm{a}=\mathrm{a}-{ }^{\mathrm{a}} \mathrm{O}, \mathrm{b}=\mathrm{b}-{ }^{\mathrm{b}} \mathrm{O}$ and $\mathrm{L}=\mathrm{L}-{ }^{\mathrm{L}} \mathrm{O}$

Subscript "O" indicates color of the control, Hue angle (tan-1 b/a) and saturation index $[\sqrt{a 2+b 2}]$ will also calculated. 


\section{Sensory evaluation}

Sensory evaluation was carried on for different product's characteristics: color, odor, taste, flavor, viscosity, and overall acceptability. Organoleptic evaluation was carried out by 15 well trained from (National Research Centre - Cairo -Egypt) Using a score sheet. All characteristics were evaluated from 1-5 degree (1 represents very poor and 5 represents very good general acceptability) according to Penfield and Campbell, (1990).

\section{Statistical analysis}

The statistical analysis will carry out using SAS statistical software; the results were expressed as (mean $\pm \mathrm{SD}$ ). Data were analyzed by one way analysis of variance (ANOVA). The differences between means were tested for significance using least significant difference test (LSD) at $(\mathrm{P}<0.05)$ (SPSS, 1986).

\section{Results and discussion}

\section{1- Microbiological Evaluation}

In this part of study, the presented data showed the state of probiotics in non-dairy fruit juice that supplemented with inulin fibers. Table (1) and figure (1) present the count development that expressed as $(\log \mathrm{cfu} / \mathrm{ml})$ of $L b$. acidophilus in guava juice. Results showed that either in the presence or absence of inulin fibers, the probiotic count was kept higher than the critical value (6 log cfu/ml). This may be the effect of high nutritional content of guava pulp, which was recommended by Ismail et al., (2017) to enhance the viability of Lactic acid bacteria and Bifido bacteria in Rayeb milk. They reported that Guava pulp has a high content of vitamins, minerals that improve the activity of lactic and probiotic starters. After addition of inulin, there was a significant difference $(\mathrm{p}<0.05)$ in Lb. acidophilus between $\mathrm{T}_{5}$ (with inulin) and $\mathrm{T}_{6}$ (without inulin) over storage periods. Upon comparing the Lb. acidophilus viable counts, it was found that in the presence of inulin in $T_{5}$, the growth was increased over $T_{6}$ by $0.2 \log$ cfu and $0.5 \log$ cfu after 2 and 3 weeks respectively.

Also, the total viable count was seen to be slowly increased reaching $7.2 \pm 0.03 \mathrm{log} \mathrm{cfu} / \mathrm{ml}$ in T5 with inulin at the end of the storage period (3rd week), while in the absence of inulin, there was no difference in total count $(6.9 \mathrm{log} \mathrm{cfu} / \mathrm{ml})$ between the start and the end of storage period. The increased total count in T5 is simply attributed to the stimulating effect of inulin toward microbial populations.

In contrast, there was no detected growth for Coliforms nor E. coli, even molds and yeasts during the 3 weeks cold storage period for all treatments. This recorded absence of these food borne concerns represents a clear evidence on efficiency of heat treatment, and the following of the proper hygienic procedures during preparation and storage of guava juice and other additives (Aneja et al., 2014).

Table 1: Microbiological examination of probiotic Guava juice with Lb. acidophilus during storage period at refrigerator temp. $\left(2-6^{\circ} \mathrm{C}\right)$.

\begin{tabular}{|c|c|c|c|c|c|c|c|}
\hline \multirow{2}{*}{\multicolumn{2}{|c|}{ Treatments }} & \multicolumn{6}{|c|}{ Microbial Count $(\log$ CFU/ml) } \\
\hline & & Coliforms Count & E. coli & Lb. acidophilus & Molds & Yeasts & Total Viable Count \\
\hline \multirow{4}{*}{$\mathbf{T}_{\mathbf{5}}$} & 0 time & Nil & Negative & $7.0 \pm 0.02$ & Nil & Nil & $6.9 \pm 0.01$ \\
\hline & 1 week & Nil & Negative & $6.9 \pm 0.03$ & Nil & Nil & $7.0 \pm .02$ \\
\hline & 2 weeks & Nil & Negative & $6.9 \pm 0.02$ & Nil & Nil & $6.8 \pm 0.00$ \\
\hline & 3 weeks & Nil & Negative & $6.9 \pm 0.01$ & Nil & Nil & $7.2 \pm 0.03$ \\
\hline \multirow{4}{*}{$\mathbf{T}_{6}$} & 0 time & Nil & Negative & $7.0 \pm 0.01$ & Nil & Nil & $6.9 \pm 0.01$ \\
\hline & 1 week & Nil & Negative & $6.9 \pm 0.00$ & Nil & Nil & $7.0 \pm 0.02$ \\
\hline & 2 weeks & Nil & Negative & $6.7 \pm 0.03$ & Nil & Nil & $6.8 \pm 0.00$ \\
\hline & 3 weeks & Nil & Negative & $6.4 \pm 0.05$ & Nil & Nil & $6.9 \pm 0.01$ \\
\hline
\end{tabular}

Data expressed as Mean \pm st. error, $\mathrm{P}<0.05, \mathbf{T}_{5}:$ Lb. acidophilus +inulin, $\mathbf{T}_{6}:$ Lb. acidophilus without inulin* 


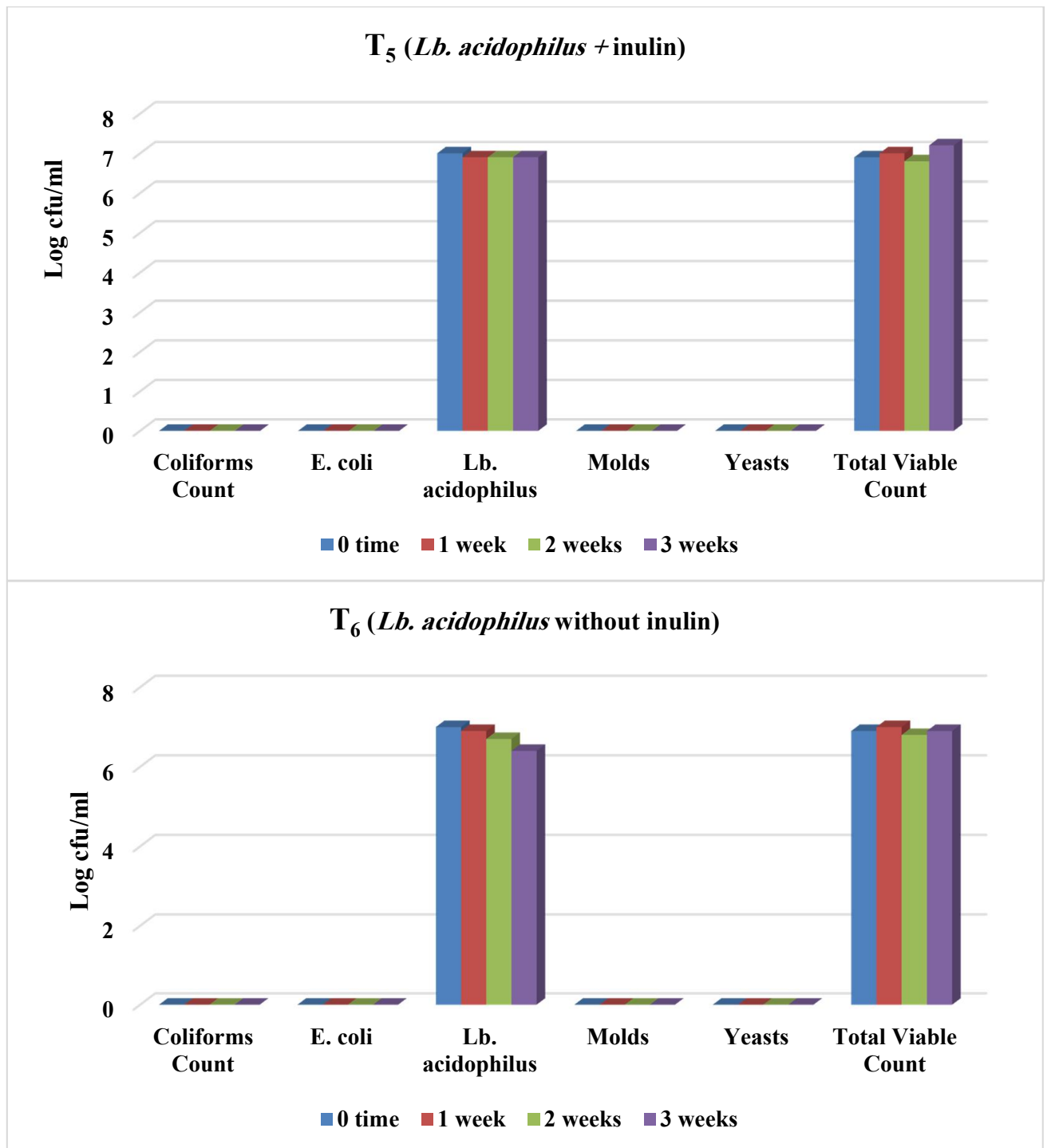

Fig. 1: Microbiological examination of probiotic Guava juice with $L b$. acidophilus during storage period at refrigerator temp. $\left(2-6^{\circ} \mathrm{C}\right)$

Table (2) and Figure (2) were presented the count development of Lb. rhamnosus that expressed as $\log \mathrm{cfu} / \mathrm{ml}$ in guava juice. Results showed that there was a significant difference $(\mathrm{p}<0.05)$ in $L b$. rhamnosus between $\mathrm{T}_{7}$ (with inulin) and $\mathrm{T}_{8}$ (without inulin) over storage periods. Upon comparing $L b$. rhamnosus viable counts, it was found that in the presence of inulin in $\mathrm{T}_{7}$, the growth was increased over $T_{8}$ by $0.1 \log$ cfu, $0.3 \log$ cfu and $0.9 \log$ cfu after 1 week, 2 weeks and after 3 weeks respectively. It appeared that $L b$. rhamnosus was encouraged by the addition of inulin to guava juice more than $L b$. acidophilus. Such results were observed by Önal Darilmaz et al., (2019) who found that, the maximal probiotic growth that stimulated by inulin differs from one strain to another. They explained the enhancing effect of this polysaccharide; inulin by the increased level of fructose as a result of partial hydrolysis of inulin by probiotics through glycolytic pathways as described by Oliveira et al., (2012).

Also, the total count was seen in T7 (with inulin) to be reduced than T8 (without inulin) by 0.6, 0.2 , and $1.2 \log \mathrm{cfu} / \mathrm{ml}$. it appears that, the more the count of Lb. rhamnosus increases the more the total count decreases due to the increased competition on the available nutrients. In addition, the released acid, by $L b$. rhamnosus growth in case of T7, retarded the growth of all flora other than acid-tolerant $L b$. rhamnosus. The results revealed that, there was no growth of total coliforms, E. coli, molds and yeasts in all treatments during storage $(3$ weeks $)$ at refrigerator temperature $\left(2-6{ }^{\circ} \mathrm{C}\right)$. 
Table 2: Microbiological examination of probiotic Guava juice with Lb. rhamnosus during storage period at refrigerator temp. $\left(2-6^{\circ} \mathrm{C}\right)$

\begin{tabular}{cccccccc}
\hline & & & \multicolumn{2}{c}{ Microbial Count (log CFU/ml) } \\
& & Coliforms Count & E. coli & Lb. rhamnosus & Molds & Yeasts & Total Viable Count \\
\hline & 0 time & Nil & Negative & $6.9 \pm 0.01$ & Nil & Nil & $6.7 \pm 0.04$ \\
T7 & 1 week & Nil & Negative & $7.0 \pm 0.02$ & Nil & Nil & $6.2 \pm 0.03$ \\
& 2 weeks & Nil & Negative & $7.1 \pm 0.03$ & Nil & Nil & $7.1 \pm 0.03$ \\
& 3 weeks & Nil & Negative & $7.7 \pm 0.04$ & Nil & Nil & $6.6 \pm 0.05$ \\
& 0 time & Nil & Negative & $6.9 \pm 0.03$ & Nil & Nil & $6.7 \pm 0.04$ \\
T8 & 1 week & Nil & Negative & $6.9 \pm 0.03$ & Nil & Nil & $6.8 \pm 0.05$ \\
& 2 weeks & Nil & Negative & $6.8 \pm 0.04$ & Nil & Nil & $7.3 \pm 0.02$ \\
& 3 weeks & Nil & Negative & $6.8 \pm 0.03$ & Nil & Nil & $7.8 \pm 0.04$ \\
\hline
\end{tabular}

*Data expressed as Mean \pm st. error, $\mathrm{P}<0.05, \mathbf{T}_{7}:$ Lb. rhamnosus + inulin, $\mathbf{T}_{\mathbf{8}}:$ Lb. rhamnosus without inulin
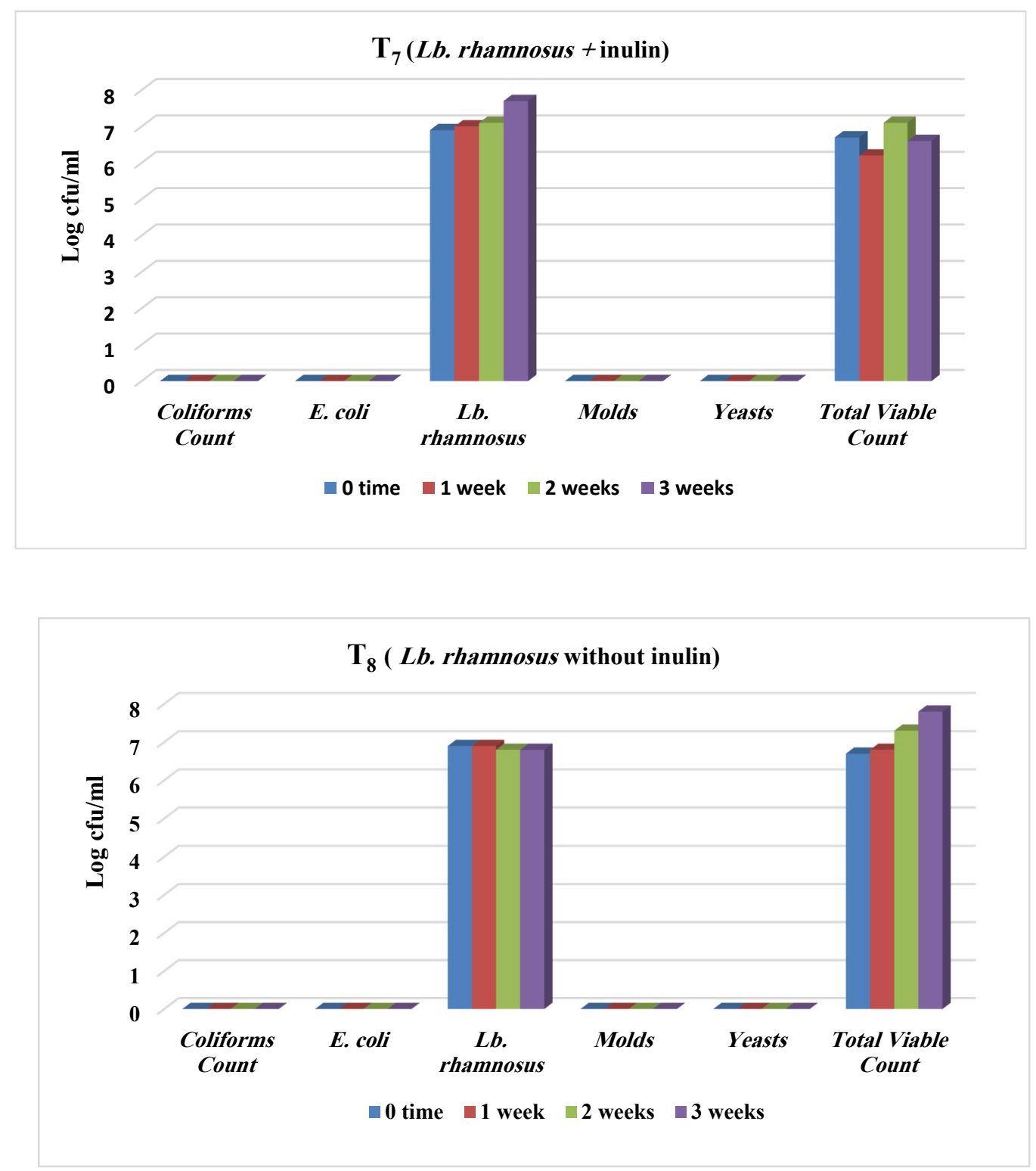

Fig. 2: Microbiological examination of probiotic Guava juice with $L b$. rhamnosus during storage at refrigerator temp. $\left(2-6^{\circ} \mathrm{C}\right)$ 


\section{Objective Evaluation Include}

\subsection{Chemical Examinations}

2.1.1- Changes in sugars values

Data presented in Figs ( $3 \mathrm{a}, \mathrm{b}$ and $\mathrm{c}$ ) showed the Changes in sugars values of guava juices treated with or without inulin and two different strains of probiotic during storage ( 0 time (fresh) and after 3 weeks at temp $\left(2-6{ }^{\circ} \mathrm{C}\right)$. From this data it could be observed that the total sugars contain ranged from $(12.37-12.38) \mathrm{g} / 100 \mathrm{ml}$ of guava juice. Non- reducing sugars was formed the highest percentage of total sugars. The main values of non-reducing sugars ranged from (10.57-10.68 \%) while the reducing sugars recorded $1.7-1.8 \%$ only. Data in the figs $(3 \mathrm{a}, \mathrm{b}$ and $\mathrm{c}$ ) illustrated that the Changes in sugars values of guava juices after storage 3 weeks, the total sugars were totally decreased especially nonreducing sugars, whereas reducing sugar were increased.

Although the growth of (Lb. acidophilus and Lb. rhamnosus) during storage was expected to reduce the concentration of reducing sugars but the value of reducing sugars was increased (Figure .3) the hydrolysis of inulin into fructose and glucose could have masked the amount of sugars consumed by (Lb. acidophilus and Lb. rhamnosus). During storage, our results were in line with findings of Lee et al., (2013) who reported that, the decrease in sucrose could be ascribed to the acid and / or enzymatic hydrolysis.

The concentrations of reducing and non-reducing sugars were measured to determine the consumption of glucose or fructose by Lb. acidophilus and Lb. rhamnosus or degradation of inulin to fructose. In this study, inulin was added into guava juice, are as a polymer of fructose molecules with glucose molecules attached at the terminal end. During storage, these molecules could have been partially hydrolyzed into their monomers (Matusek et al., 2009). As a consequence the concentration of reducing sugars in probiotic guava juices increased due to the supplementation of inulin (figure 3).

These results are in agreement with Bibas Bonet et al., (2010) who studied the effect of storage on FOS of yacon and the result showed the conversion of FOS to glucose, fructose, and sucrose at a temperature higher and lower than $10^{\circ} \mathrm{C}$ which might be the reason for the increase in reducing sugar value. Also, these results are in agreement with Kashudhan et al., (2017) who reported that the refrigerated storage can cause hydrolysis of oligo- and polysaccharides into simpler carbohydrates or hydrolysis of sucrose to invert sugars.

\subsubsection{Changes in vitamin $C$ content}

For concerning of vit.c, it's quantity in guava juices ranged from (105-105.2) mg/ 100ml juice for control and all treated samples. While, changes in vitamin C content after storage 3 weeks in fig. (4) showed that, there are changed in the value of vitamin $\mathrm{C}$ during storage of guava juices treated with or without inulin and different probiotic strains (Lb. acidophilus \& Lb. rhamnosus) at refrigerator temp $\left(2-6 C^{\circ}\right)$.

During storage vitamin $\mathrm{C}$ was slightly reduced, this results indicated that, the processing and storage of the beverages were suitable, as vitamin $\mathrm{C}$ is an unstable compound and prone to oxidation, it breaks down easily and degrades steadily during storage (Kashudhan et al., 2017). Furthermore, the phenolic compounds are sensitive to oxidation when exposed to oxygen, heat, and light (Porto et al., 2018). The use of glass flasks and the low storage temperature $\left(6^{\circ} \mathrm{C}\right)$ may have contributed to the preservation of vitamin C (Miranda et al., 2019).

Also, these results are in agreement with Filannino et al., (2013) who said that fermentation of juice by Lactobacillus acidophilus preserves the bioactive component of the yacon juice. 


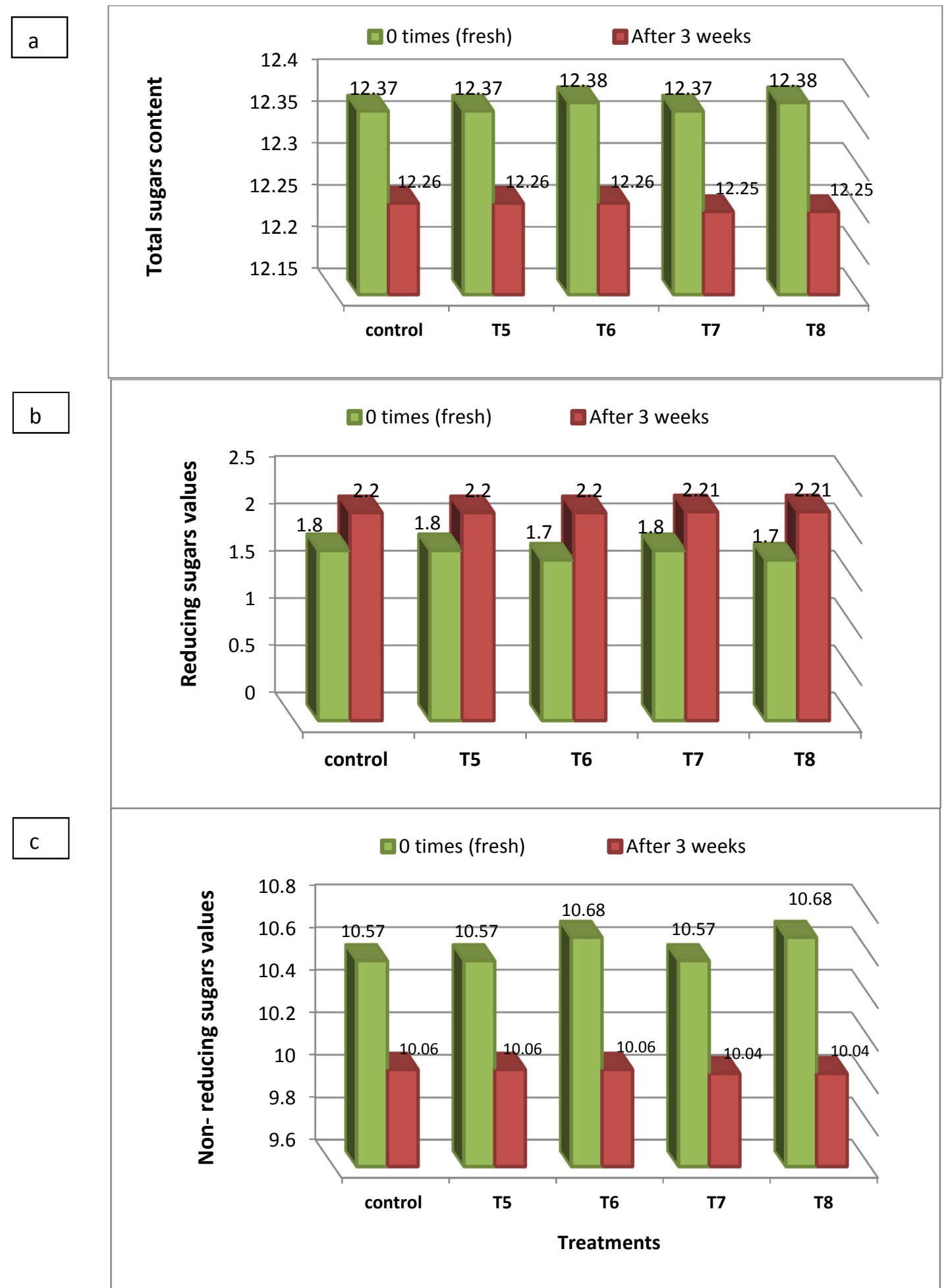

Fig. (3 a, b, \& c ): Total sugars, Reducing sugars and non- reducing sugars content of fresh Guava juices treated with or without inulin and two different strains of probiotic $(L b$. acidophilus \& Lb. rhamnosus) and during storage at temp $\left(2-6^{\circ} \mathrm{C}\right)$ for 3 weeks. 


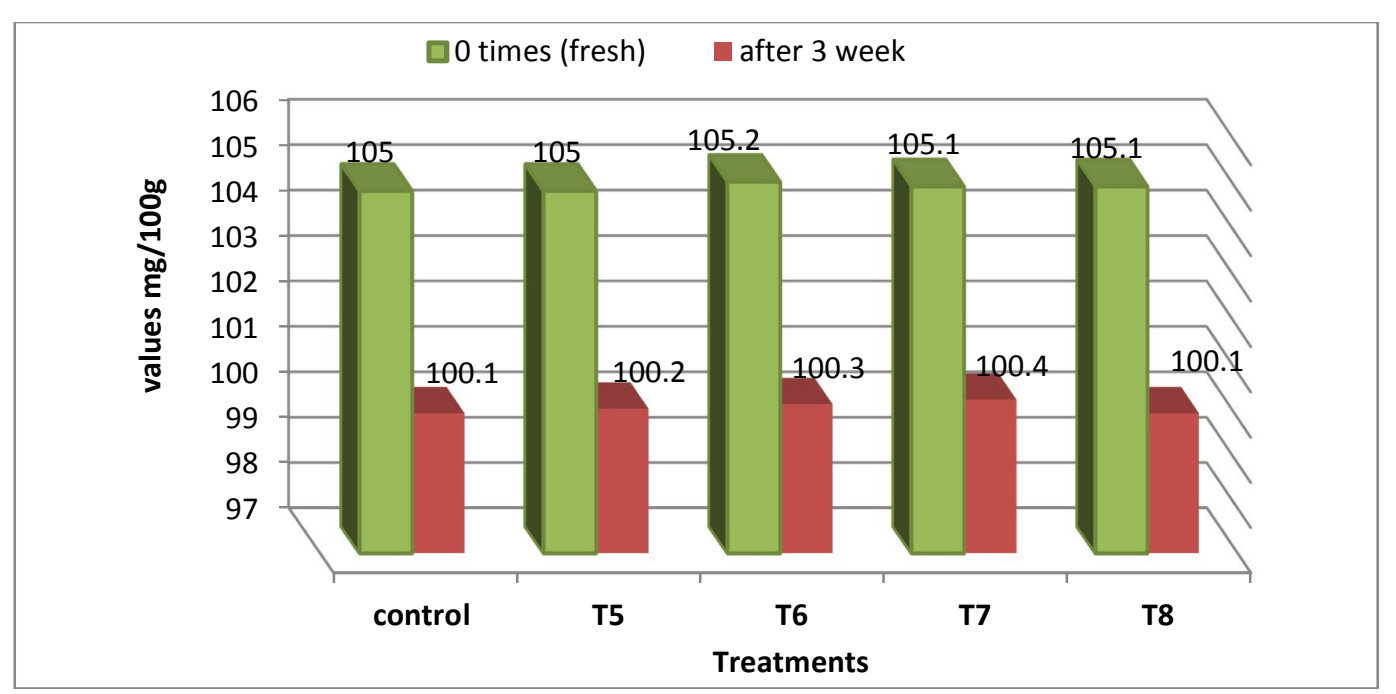

Fig. 4: Vitamin C content of fresh Guava juices treated with or without inulin and two different strains of probiotic (Lb. acidophilus \& Lb. rhamnosus) and during storage at temp $\left(2-6^{\circ} \mathrm{C}\right)$ for 3 weeks

\subsection{Physico-chemical analysis}

\subsubsection{PH values and Titratable acidity}

$\mathrm{PH}$ is one of the chief significant factors affecting the probiotic viability. Figure (5) shows the changes in PH values and Titratable acidity of guava juice treated with or without $2 \%$ inulin and two different probiotic strains ( $\mathrm{Lb}$. acidophilus and Lb. rhamnosus) during storage ( 0 time, 1 week, 2 week and 3 weeks) at refrigerator temp $\left(2-6^{\circ} \mathrm{C}\right)$.

Although the guava juice had an initial $\mathrm{PH}$ value of 4.5 , it could be noticed from these data decreased in $\mathrm{pH}$ values of guava juice during storage in all treated samples $\mathrm{T}_{1}, \mathrm{~T}_{2}, \mathrm{~T}_{3}$ and $\mathrm{T}_{4}$ compared with the value of control in both fresh( 0 time) and after storage for 1 week, 2 week and 3 weeks at (2$6{ }^{\circ} \mathrm{C}$ ) were as the same (4.19). The highest value of $\mathrm{PH}$ was noticed in the treated samples with $2 \%$ inulin, $\mathrm{T}_{5}$ were $4.19,4.17,4.12,4.05$ respectively and in $\mathrm{T}_{7}$ were $4.19,4.18,4.09$ and 4.07 respectively, while the lowest value of $\mathrm{PH}$ was noticed in the treated samples without addition of $2 \%$ inulin. The values $\mathrm{T}_{6}$ were $4.19,4.17,4.14$ and 4.09 respectively and in $\mathrm{T}_{8}$ were $4.19,4.18,4.12$ and 4.12 respectively.

These results are in agreement with those of Ertem and Çakmakçı, (2018) they mentioned that beverage $\mathrm{pH}$ was also decreased gradually over the study period as a result of the production of lactic acid by L. acidophilus which is known as post- fermentation. Also, these results are in agreement with those of Mousavi et al. (2011) they mentioned that Growth of probiotic organisms in an appropriate medium contributes to the release of organic acid (lactic acid) and consequently decreases the $\mathrm{pH}$ value of the substrate. These results are consistent with those reported by Czyżowska et al., (2006) who studied lactic acid fermentation of red beet juice using L. plantarum and L. casei strains ( $\mathrm{pH}$ was decreased to $3.5-4.0)$.

Figure (5) illustrated the decreased in $\mathrm{pH}$ during storage appeared to be positively correlated with the increasing TA; whereby, as lactic acid is produced the $\mathrm{pH}$ decreases and the TA increases. Values of TA in all treated samples and control at 0 time, ranged from (0.51- 0.52$) \%$ only, after storage 3 week all treated samples and control had high values of TA it ranged from (0.57- 0.58$) \%$ only. The highest value of TA was noticed in the all treated samples with $2 \%$ inulin $_{5}$ and $\mathrm{T}_{7}$, the values were $(0.58) \%$ after 3 weeks. While, the lowest value of TA was noticed in the treated samples without addition of $2 \%$ inulin $\mathrm{T}_{6}$ and $\mathrm{T}_{8}$. The values were $(0.57) \%$. This could be due to the fact that inulin enhancing the growth rate of probiotic strains as bifidogenic factor. These results are in agreement with those of Tuohy et al., (2001). They are cleared that inulin increasing population of lactobacillus.

The present results agreement with Pereira et al., (2018) who reported that an association of probiotic viability with the intrinsic characteristics of the beverages such as acidity. Also, these results are in agreement with Oliveira et al. (2012) find that acidification profile in yoghurt production can be affected by inulin supplementation, they illustrated that the bacterial count concentration in the presence of inulin in medium is significantly more. 


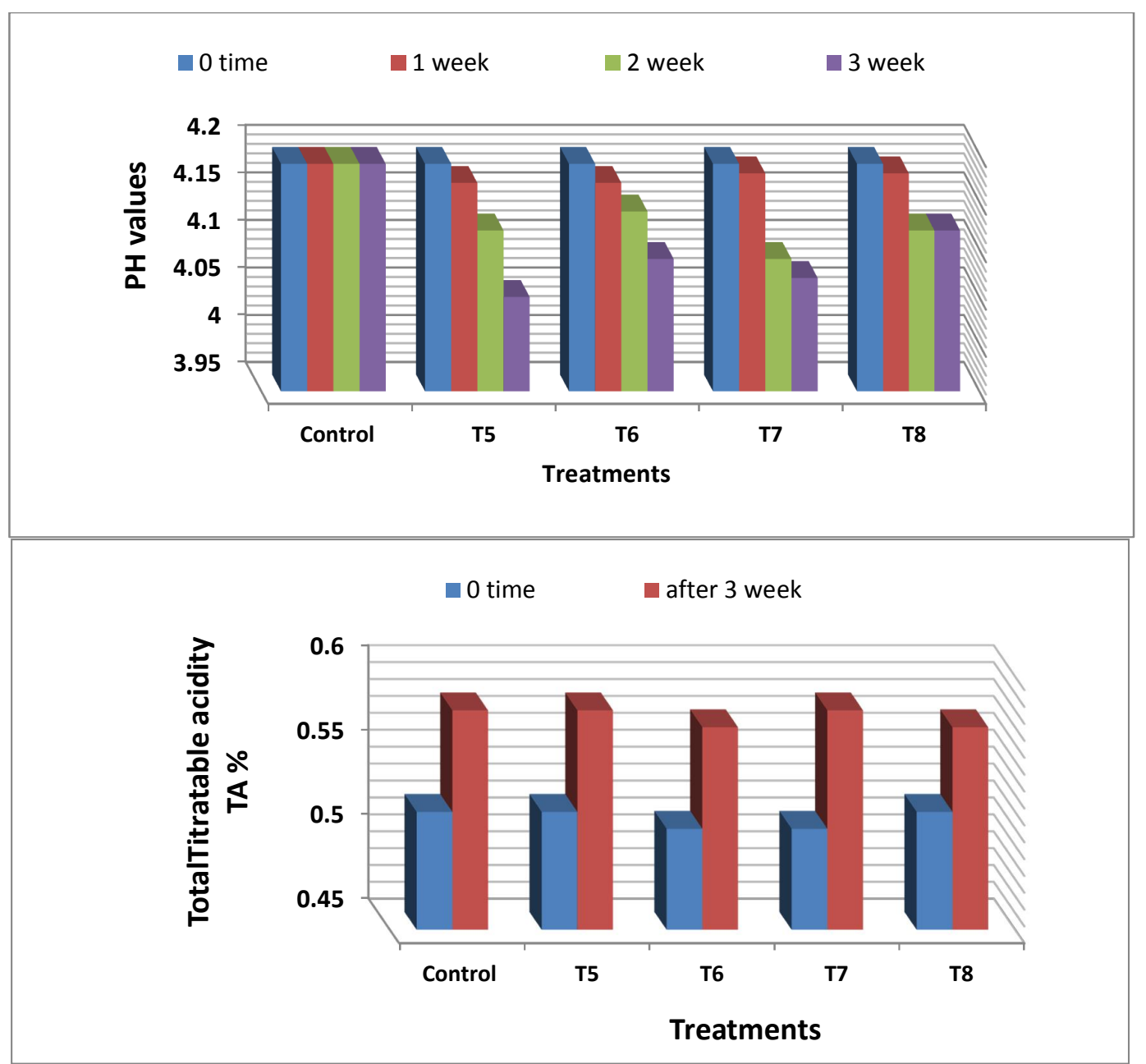

Fig. 5: Changes PH and Total Titratable acidity values TA\% of guava juice treated with or without $2 \%$ inulin and two different probiotic strains (Lb. acidophilus and Lb.rhamnosus) during storage at refrigerator temp $\left(2-6^{\circ} \mathrm{C}\right)$

\subsubsection{Total soluble solids (TSS)}

Figure (6) illustrated the values of total soluble solids (TSS) of guava juice treated with or without $2 \%$ inulin and two different probiotic strains (Lb. acidophilus and Lb. rhamnosus) in both fresh (0 time and after 3 week) at refrigerator temp $\left(2-6^{\circ} \mathrm{C}\right)$, there no changes of the values of (TSS) for treated samples in both fresh and after storage for 3 weeks at $\left(2-6^{\circ} \mathrm{C}\right)$. The value were as the same (8.8) \% only. The proliferation of $L b$. acidophilus and Lb. rhamnosus in guava juice was expected to decrease the TSS of the juice due to their sugar consumption. However, no changes were observed in the TSS of probiotic juices Figure (6).

This discrepancy is also observed by Di Cagno et al., (2011) and Koh et al., (2010) in the fermentation of mixed fruit and vegetable juice and tomato juice, respectively. Lactic acid, which is produced during the fermentation of sugars by probiotic, might be responsible for the insignificant changes of TSS. Furthermore, TSS is only an approximate measure of soluble solids, hence minor changes in the sugar and organic acid level caused by fermentation and storage may not be evident using this measurement.

The present results are in agreement with Tarakci and Kucukoner, (2003). They reported that determined $18.25 \%$ and $17.69 \%$ TSS in date pulp and grape molasses yogurts, respectively. The variation of TSS recommends that, the total solid content not only depends on mixed fruit in the formulation but also it depends on the added sugar and inherent sugar and fiber contents of the fruit. Also in agreement with Verma and Joshi, (2000). They showed that TSS in fruit juices is largely 
contributed by sugars $(90 \%-95 \%)$. However, other minor compounds, such as organic acids, pigments and amino acids in fruit juices are also involved in the measurement of TSS.

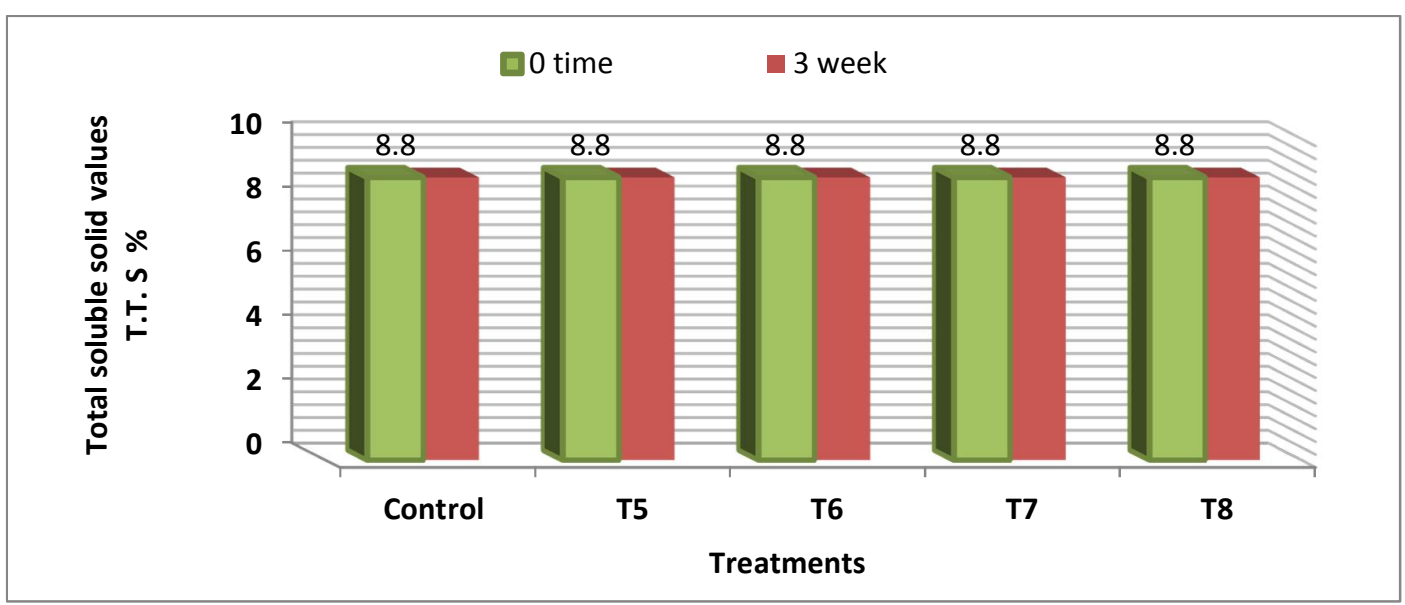

Fig. 6: Total soluble solids values (T.S.S) of guava juice treated with or without $2 \%$ inulin and two different probiotic strains (Lb. acidophilus and Lb. rhamnosus) during storage at refrigerator temp $\left(2-6^{\circ} \mathrm{C}\right)$.

\subsection{Physical properties}

\subsubsection{Viscosity (cps)}

Figure (7) illustrated the viscosity values of guava juice treated with or without $2 \%$ inulin and two different probiotic strains (Lb. acidophilus and Lb. rhamnosus) in both fresh (0 time and after 3 week) at refrigerator temp $\left(2-6^{\circ} \mathrm{C}\right)$, It is obvious from these results that the viscosity value of $\mathrm{T}_{5}$ was (1655.1 cps), $\mathrm{T}_{7}$ was $(1653.6 \mathrm{cps})$ at 0 times (fresh), but a significant difference was noticed between the formulation containing of this treatment $(2 \%$ inulin) with the same strains but without inulin at 0 times $\mathrm{T}_{6}$ was $(1654.3 \mathrm{cps}), \mathrm{T}_{8}$ was $(1651.1 \mathrm{cps})$ when fresh.

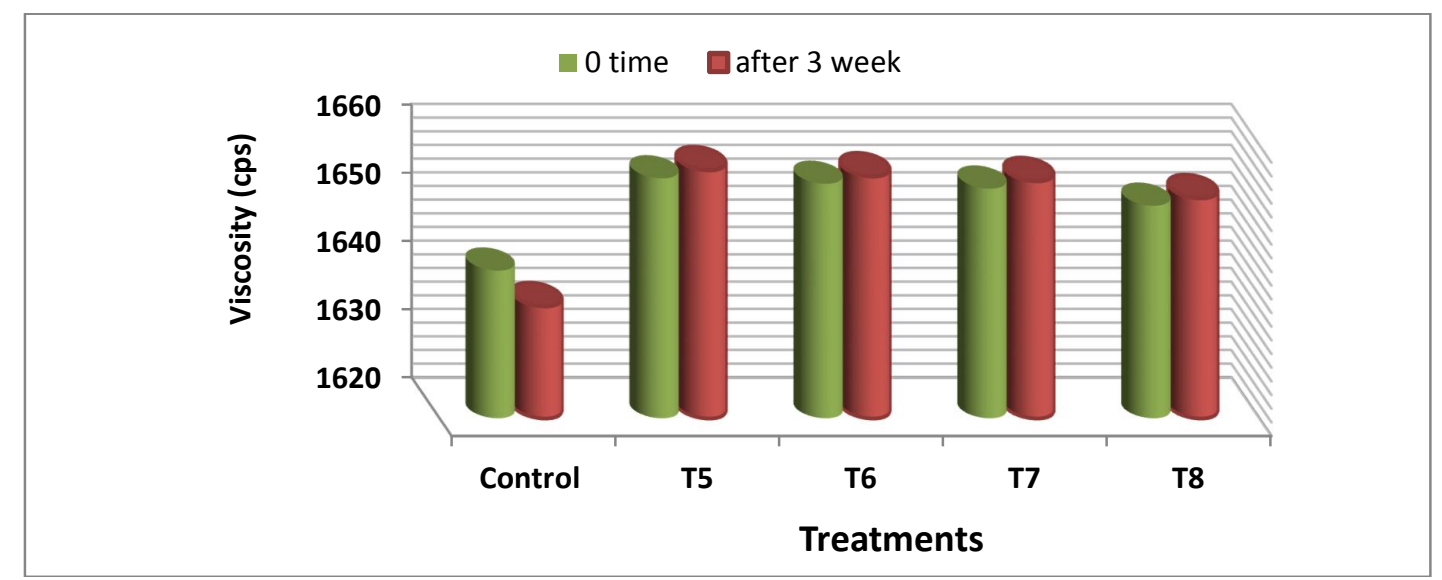

Fig. 7: Changes in the viscosity values of Guava probiotic with or without $2 \%$ inulin and two different probiotic strains (Lb. acidophilus and Lb. rhamnosus) during storage at refrigerator temp (2 $\left.6{ }^{\circ} \mathrm{C}\right)$.

The viscosity was gradually increased throughout the storage period to reaching a maximum after 3 week in treated samples with $2 \%$ inulin, $\mathrm{T}_{5}$ was $(1656.3 \mathrm{cps}), \mathrm{T}_{7}$ was $(1654.7 \mathrm{cps})$ while, the lowest value was noticed in treated samples without inulin $T_{6}$ and $T_{8}$ were $(1655.4$ and 1652.2$)$ cps resp. It could be noticed from these data that all treatments with or without inulin had a higher viscosity when fresh and throughout the storage compared to the value of control in both fresh and after storage 3 week were (1641.6 and 1636.4) cps resp. The results indicated that, there was a significant positive relationship between viscosity and the amount of added inulin. These results are in agreement with 
Debon et al., (2012) and Hekmat et al., (2015). They cleared that, the apparent viscosity of the product contains inulin increased with storage time; inulin fiber is a type of prebiotic that is a low calorie sweetener and fat substitute that acts as a bulking agent. Also agreement with Bayarri et al., (2011) who showed that, an increase in most rheological parameters when long-chain inulin was used in low-fat dairy desserts, which was attributed to the presence of inulin aggregates.

Also, these results are steady with those reported by Costa et al., (2017) who indicated that, the increased viscosity detected in the fruit juices could be related to the ability of some Lactobacillus species to produce exopolysaccharides that may act as texturizing agents, increasing the viscosity of the final product and interacting with the other juice constituents (e.g., proteins).

\subsubsection{Color of guava juices}

Color is an important quality indicator in terms of nutritive value and attractiveness of various food products, including fruit juices during processing and storage and there is a considerable interest when making beverage with fruits to achieve the right goal for consumers. So, Table (3) had indicated color of probiotic guava juice with or without $2 \%$ inulin and two different probiotic strains $(L b$. acidophilus, Lb. rhamnosus $)$ at refrigerator temp $\left(2-6{ }^{\circ} \mathrm{C}\right)$ during period storage $(0$ time and after 3 weeks).

Table 3: Hunter color values of guava juice treated with or without $2 \%$ inulin and two different probiotic strains (Lb. acidophilus and Lb. rhamnosus) during storage (0 time and after 3 weeks) at refrigerator temp $\left(2-6^{\circ} \mathrm{C}\right)$.

\begin{tabular}{lccccc}
\hline & \multicolumn{5}{c}{ Fresh (At 0 time) } \\
Parameters & Control & $\mathbf{T}_{\mathbf{5}}$ & $\mathbf{T}_{\mathbf{6}}$ & $\mathbf{T}_{\mathbf{7}}$ & $\mathbf{T}_{\mathbf{8}}$ \\
\hline $\mathbf{L}^{*}$ & 65.21 & 66.77 & 69.56 & 68.52 & 68.41 \\
$\mathbf{a}^{*}$ & -1.4 & -1.18 & -0.99 & -1.26 & -1.1 \\
$\mathbf{b}^{*}$ & 18.3 & 16.65 & 17.31 & 16.73 & 16.84 \\
a/b & -0.07 & -0.07 & -0.05 & -0.08 & -0.07 \\
Saturation & 18.24 & 16.60 & 17.28 & 16.86 & 16.80 \\
Hue & -0.23 & -0.25 & -0.31 & -0.24 & -0.27 \\
\hline & \multicolumn{7}{c}{ After (3 weeks) } & & $\mathbf{T}_{\mathbf{8}}$ \\
Parameters & Control & $\mathbf{T}_{\mathbf{5}}$ & $\mathbf{T}_{\mathbf{6}}$ & 67.27 \\
\hline $\mathbf{L}^{*}$ & 64.22 & 66.57 & 67.7 & 67.39 & -0.5 \\
$\mathbf{a}^{*}$ & -1.04 & -0.49 & -0.80 & -0.61 & 16.58 \\
$\mathbf{b}^{*}$ & 15.35 & 16.05 & 16.01 & 16.32 & -0.03 \\
a/b & -0.06 & -0.03 & -0.04 & -0.04 & 16.57 \\
Saturation & 15.31 & 16.04 & 16.02 & 16.31 & -0.65 \\
Hue & -0.26 & -0.64 & -0.36 & -0.50 & \\
\hline
\end{tabular}

$* \mathbf{b}=$ yellowness $* \mathbf{L}=$ lightness $* \mathbf{a}=$ redness.

$\mathbf{T}_{5}$ : Lb. acidophilus +inulin, $\mathbf{T}_{6}:$ Lb. acidophilus without inulin, $\mathbf{T}_{7}:$ Lb. rhamnosus +inulin, $\mathbf{T}_{8}:$ Lb. rhamnosus without inulin

Obviously, there were significant differences between the color parameter at 0 times and after 3 week storage. Lightness values of all treated samples and control at 0 time ranged from (65.21- 69.56) only. While $\mathrm{T}_{5}, \mathrm{~T}_{6}, \mathrm{~T}_{7}$ and $\mathrm{T}_{8}$ were found to be lower values $(66.57,67.7,67.39$ and 68.27$)$ respectively after storage 3 week; while the treated samples values were higher than the value of control in both fresh and after storage 3 week were (65.21 and 64.22) respectively, we notice that inulin and different probiotic strains (Lb. acidophilus and Lb. rhamnosus) had influenced the color of treated samples; it contributed to slightly decrease lightness (L) parameters during storage period; it could be caused by the growth cultures of Lb. rhamnosus and Bifidobacterium breve.

These results are in agreement with El-Hatmi et al., (2018) who cleared that, in addition to milk used, the use of different starter cultures might affect the color values.

Redness (a) of all treated samples and control at 0 time ranged from (-0.99- -1.4) only. While redness (a) of $\mathrm{T}_{5}, \mathrm{~T}_{6}, \mathrm{~T}_{7}$ and $\mathrm{T}_{8}$ had redness values lower $(-0.49,-0.80,-0.61$ and -0.5$)$ respectively than that of the control (-1.04) after storage 3 week.

Yellowness of all treated samples and control at 0 time ranged from $(16.65: 18.3)$ only. After 3 week Yellowness of $T_{5}, T_{6}, T_{7}$ and $T_{8}$ had values higher $(16.05,16.01,16.32$ and 16.58) respectively 
than that of the control (15.35). There was fluctuation in the other color parameters ( $a^{*}$ and $b^{*}$ ) in all treatments samples at the end storage period.

These results are in agreement with Pimentel et al., (2015) who reported that, the color intensification in some days of storage could have been related to nonoxidative and oxidative reactions of polyphenols, resulting in colored condensation products; and to a lesser extent, by the Maillard reaction or formation of melanoidins.

Saturation values (which indicated degrees of color intensity) of all treated samples and control at 0 time ranged from $(16.60-18.24)$ only while, the values of all treated samples $\mathrm{T}_{5}, \mathrm{~T}_{6}, \mathrm{~T}_{7}$ and $\mathrm{T}_{8}$ were higher values $(16.04,16.02,16.31$ and 16.57 ; respectively than that of the control (15.31) after storage 3 weeks.

These results are in agreement with Da Costa et al., (2017) who showed that may be related to ascorbic acid interaction with pigments of the juices, resulting in the decrease in the color intensity.

Hue angle showed the relation of hunter redness (a) and yellowness (b) color scores on a polar plan as a compared to control. The tabulated results indicated that, all treated samples and control at 0 time ranged from (- $0.23--0.31)$ only; the values of treated samples at the end of storage $T_{5}, T_{6}, T_{7}$ and $\mathrm{T}_{8}$ were higher values $(-0.64,-0.36,-0.50$, and -0.65$)$ respectively than that of the control $(-0.26)$. From the previous results it can be concluded that, the effect of inulin and different probiotic strains on guava juice color was greater and noticeable.

The present result was in agreement with the finding reported by Majchrzak et al., (2010)who reported that, the changes in color values of probiotic dairy drinks during storage may result from the changes in $\mathrm{pH}$ as a result of increased acidity in the product. This is due to the growth cultures of $L b$. acidophilus and Lb. rhamnosus.

\section{Sensory evaluation}

Sensory evaluation of results for probiotic guava juice with or without inulin and different probiotic strains ( $\mathrm{Lb}$. acidophilus and Lb. rhamnosus) at refrigerator temp $\left(2-6^{\circ} \mathrm{C}\right)$ during storage period are shown in Figure (8).

The tabulated results showed that, all treatments were not different significantly $(p<0.05)$ in the color, odor, viscosity and overall acceptability of probiotic guava juice as compared to control after 7 Days of storage. These results were agreement with Ellendersen et al., (2012) who reported that a challenge for probiotic fortification of juices is product acceptance by consumers. While, taste scores had significant increase in treatments $\mathrm{T} 6, \mathrm{~T}_{7}$ and $\mathrm{T}_{8}(4.3 \pm 0.11,4.6 \pm 0.14$ and $4.7 \pm 0.11)$ respectively as compared to control (3.3 \pm 0.13 ), also Flavor scores had significant increase in treatments $\mathrm{T}_{7}$ and $\mathrm{T}_{8}$

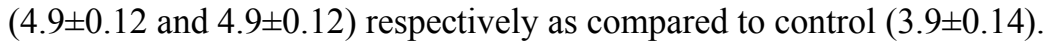

According to the data presented in Figure (8), it was found that all treatments were nonsignificant at $(\mathrm{P}<0.05)$ in the color, Taste, flavor, viscosity and overall acceptability of probiotic guava juice and this after 2 weeks of the storage as compared to control sample. Meanwhile, the odor score had significantly decreased $(p<0.05)$ in $T_{5}$ treatment which had $3.1 \pm 0.15$ compared to control juice (4.2 \pm 0.17$)$, nevertheless it's considered not poor according to score sheet of 5-points ( $1=$ lowest quality to5= highest quality) according to Penfield and Campbell, (1990), thus it consider acceptable to the panelists in odor characteristic of sensory evaluation. The present results agree with Cais-Sokolińska et al., (2008) who reported that, the use of probiotic cultures in the production of fermented dairy drinks was effective on taste and aroma in the final product and positively affected the criteria of sensory evaluation.

Also, these results are in agreement with Canbulat and Ozcan, (2015) who reported that, inulin no off flavour, and when formulating a low-calorie fruit preparation for yoghurts using high intensity sweeteners, inulin could enhance the fruit flavour, balance the sweetness profile and mask any undesirable taste. 


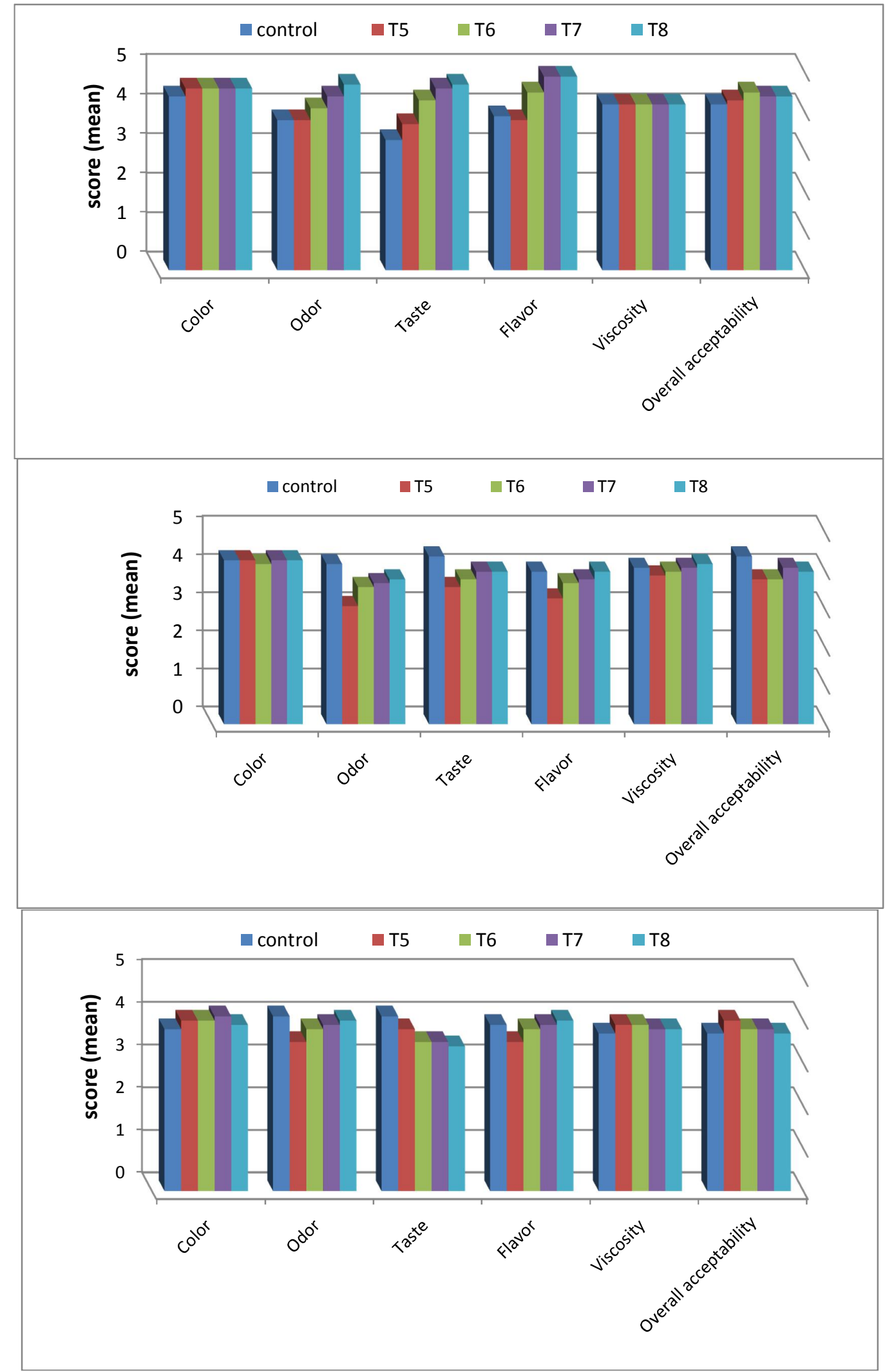

Fig. 8: Mean values of sensory characteristics of probiotic guava juice with or without inulin and different probiotic strains (Lb. acidophilus and Lb. rhamnosus) at refrigerator temp $\left(2-6^{\circ} \mathrm{C}\right)$. 
At the end of storage (after 3 weeks) data presented in Figure (8) showed no significant difference $(p<0.05)$ in all sensory characteristics (color, odor, taste, flavor, viscosity and overall acceptability) of probiotic guava juice in all treatments as compared to control sample. Moreover the results noticed that, all treatments had higher mean scores for color and overall acceptability than the control juice. Therefore, it could be noticed that, the $\mathrm{T}_{5}, \mathrm{~T}_{6}, \mathrm{~T}_{7}$ and $\mathrm{T}_{8}$ maintained better characteristics with regard to color, odor, taste, flavor, and overall acceptability. It is clear that, the overall acceptability for all the treatments of probiotic guava juice was very good even after 21 days of storage. Such organoleptic characteristics are report by Luckow and Delahunty, (2004) in non-dairy juice drinks. They showed that, consumers prefer the sensory characteristics of probiotic orange juice in comparison to conventional orange juices because of their health benefits. Ranadheera et al., (2014) underlined that; some fruit juices could naturally mask the "medicinal" taste of probiotics.

Also, these results are in agreement with Rezaei et al., (2012) who cleared that, Total acceptability of frozen yoghurts containing inulin $(0,1$ and $2 \%)$ revealed that, yoghurt with $2 \%$ inulin had the most appealing sensory characteristics.

\section{Conclusion}

Today, consumers' attention to the health diet is increasing. The development of probiotic fruit juices is possible, allowing the consumption of these beneficial microorganisms by people who do not like dairy products or with intolerance or allergy to milk components. Fruit juices represent a suitable carrier for the delivery of probiotics. Since, fruits are naturally rich in essential macro- and microelements. Inulin is described as a functional polysaccharide and its influence on human metabolism and health is studied. The prebiotic and probiotic combination and inulin bifidogenic effect are mentioned. In overall conclusion, there are two main challenges during manufacture, that is, the maintenance of the probiotic viability during the shelf life of the products and to the gastrointestinal tract and the maintenance of the physicochemical and sensory characteristics of the end products (guava juice).

\section{References}

Ahmed, Z., Y. Wang, Q. Cheng, and M. Imran, 2010. Lactobacillus acidophilus bacteriocin, from production to their application: an overview. African Journal of Biotechnology, 9(20): 28432850.

American Public Health Association (APHA), 1976. Compendium methods for the microbiological examination of foods. $1^{\text {st }}$ ed. by Marvin specked. Washington, DC, USA.

Aneja, K.R., R. Dhiman, N.K. Aggarwal and A. Aneja, 2014. Emerging preservation techniques for controlling spoilage and pathogenic microorganisms in fruit juices. International journal of microbiology.

AOAC, 2005. Official Methods of Analysis of AOAC International.18 ${ }^{\text {th }}$ Ed., AOAC International, Gaithersburg, MD, USA.

Bansal, S., M. Mangal, S.K. Sharma, and R.K. Gupta, 2016. Non-dairy Based Probiotics: A Healthy Treat for Intestine.Crit. Rev. Food Sci. Nutr.56:1856 -1867.

Bashir, H.A. and A.A. Abu-Goukh, 2003. Compositional changes during guava fruit ripening. Food Chem 80: $557-563$.

Bayarri, S., L. GonzáLez-Tomás, I. Hernando, M.A. Lluch and E. Costell, 2011. Texture perceived on inulin-enriched low-fat semisolid dairy desserts. Rheological and structural basis. J Texture Stud 42(3): 174- 84.

Bibas Bonet, M. E., O. Meson, A. de Moreno de LeBlanc, C. A. Dogi, S. Chaves, A. Kortsarz, and G. Perdigon, 2010. Prebiotic effect of yacon (Smallanthus sonchifolius) on intestinal mucosa using a mouse model. Food and Agriculture Immunology, 21 (2): 175 - 189.

Boyle, F.D., H. seagrave - smith, S. Sakata, and G.D. Sherman, 1957. Commercial guava processing in Hawaii. Bulletin of the Hawaii Agricultural Experimental Station, III.

Cais-Sokolińska, D., R. Romualda Danków and J. Pikul, 2008. Physicochemical and sensory characteristics of sheep kefir during storage. Acta Scientiarum Polonorum Technologia Alimentaria 7(2): $63-73$. 
Canbulat, Z. and T. Ozcan, 2007. The health impact of using Lactobacillus rhamnosus GG in infant formulas and children's dietary supplements. Journal of Agricultural Faculty of Uludag University, 21(1): 69-79.

Canbulat, Z. and T. Ozcan, 2015. Effects of short-chain and long-chain inulin on the quality of probiotic yogurt containing Lactobacillus rhamnosus. Journal of food processing and preservation 39: 1251- 1260 .

Costa, G.M., J.V.C. Silva, J.D. Mingotti, C.E. Barão, S.J. Klososki and T.C. Pimentel, 2017. Effect of ascorbic acid or oligofructose supplementation on L. paracasei viability, physicochemical characteristics and acceptance of probiotic orange juice. LWT Food Sci Technol 75: 195 - 201.

Czyżowska, A., E. Klewicka and Z. Libudzisz, 2006. The influence of lactic acid fermentation process of red beet juice on the stability of biologically active colorants. Eur. Food Res. Technol. 223: 110- 116 .

Da Costa, G. M., J. V. de Carvalho Silva, J. D. Mingotti, C. E. Barão, S. J. Klososki, and T. Pimentel, 2017. Effect of ascorbic acid or oligofructose supplementation on L. paracasei viability, physicochemical characteristics and acceptance of probiotic orange juice. LWT - Food Science and Technology, 75: $195-201$.

Debon, J., E. S. Prudêncio and J.C.C. Petrus, 2012. Storage stability of prebiotic fermented milk obtained from permeate resulting of the microfiltration process. LWT - Food Science and Technology 47: 96 - 102.

Di Cagno, R., G. Minervini, C. G. Rizzello, M. De Angelis and M. Gobbetti, 2011. Effect of lactic acid fermentation on antioxidant, texture, color and sensory properties of red and green smoothies. Food Microbiology, 28: 1062- 1071. https://doi.org/10.1016/j.fm.2011.02.011

El Hatmi, H., Z. Jrada, O. Oussaiefa, W. Nasria, I. Sbissic, T. Khorchania, and L.L.S. Canabady Rochelled, 2018. Fermentation of dromedary camel (Camelus dromedarius) milk by Enterococcus faecium, Streptococcus macedonicus as a potential alternative of fermented cow milk. LWT - Food Science and Technology, 90: $373-380$.

El-Hadedy, D. and S.A. El-Nour, 2012. Identification of Staphylococcus aureus and Escherichia coli isolated from Egyptian food by conventional and molecular methods. Journal of Genetic Engineering and Biotechnology, 10(1): 129-135. https://doi.org/10.1016/j.jgeb.2012.01.004

Ellendersen, L.S.N., D. Granato, B.K. Guergoletto and G. Wosiacki, 2012. Development and sensory profile of a prebiotic beverage from apple fermented with Lactobacillus casei. Eng. Life Sci. 12: $1-11$.

Ertem, H. and S. Çakmakçı, 2018. Shelf life and quality of probiotic yogurt produced with Lactobacillus acidophilus and Gobdin. International Journal of Food Science and Technology 53: 776 - 783.

FAO/WHO, 2002. Guidelines for the evaluation of probiotics in food, in Food Agric Organ United Nations World Heal Organ (Working Gr Report, Ontario, Canada).

Fazilaha, F. N., B. A. Ariff, E. M. Khayat, L. Rios-Solis and M. Halim, 2018. Influence of probiotics, prebiotics, synbiotics and bioactive phytochemicals on the formulation of functional yogurt. Journal of Functional Foods 48: $387-399$.

Ferrao, L. L., E.B. Silva and H. L. A. Silva, 2016. Strategies to develop healthier processed cheeses: Reduction of sodium and fat contents and use of prebiotics. Food Research International 86: 93 -102 .

Filannino, P., L. Azzi, I. Cavoski, O. Vincentini, C. G. Rizzello, and M. Gobbetti, 2013. Exploitation of the health-promoting and sensory properties of organic pomegranate (Punica granatum L.) juice through lactic acid fermentation. International Journal of Microbiology, 163(2-3): $184-192$.

Food and Drug Administration (FDA), 2002. Bacteriological Analytical Manual. $9^{\text {th }}$ Ed., AOAC International, Arlington, VA, USA.

Gahruie, H. H., M. H. Eskandari, G. Mesbahi, and M. A. Hanifpour, 2015. Scientific and technical aspects of yogurt fortification: A review. Food Science and Human Wellness, 4, 1-8.

https:// doi.org/10.1016/j.fshw.2015.03.002

Galloway, L.D. and R. Burgess, 1952. Applied Mycology and Bacteriology 3rd Edition Leonard Hill. London, 54 and, 57.

Guimaraes, T. J., K. E. Silva, and R. L. A. Costa, 2018. Manufacturing a prebiotic whey beverage exploring the influence of degree of inulin polymerization. Food Hydrocolloids 77: 787 - 795. 
Hekmat, S., K. Morgan, M. Soltani, and R. Gough, 2015. Sensory Evaluation of Locally-grown Fruit Purees and Inulin Fibre on Probiotic Yogurt in Mwanza, Tanzania and the Microbial Analysis of Probiotic Yogurt Fortified with Moringa oleifera. J. Health Popul. Nutr., 33: 60-67.

Hunter, R.S., 1975. Scales for measurements of color differenced. In Measurement of appearance, John Wiley ED., Interscience, New York, USA.133 P.

Ismail, M.M., M.F. Hamad, and E.M. Elraghy, 2017. Rheological, Physicochemical, Microbial and Sensory Properties of Bio-rayeb Milk Fortified with Guava Pulp. International Journal of Food Science and Biotechnology, 1(1): 8.

Kareb, O. and M. Aïder, 2018. Whey and its derivatives for probiotics, prebiotics, synbiotics, and functional foods: a critical review. Probiotics and Antimicrobial Proteins 7: 1-22.

Kashudhan, H., A. Dixit, and A. Upadhyay, 2017. Optimization of ingredients for the development of wheatgrass based therapeutical juice using response surface methodology (RSM). Journal of Pharmacognosy and Phytochemistry, 6(2): 338- 345.

Koh, J. H., Y.Kim and J. H. Oh, 2010. Chemical characterization of tomato juice fermented with Bifidobacteria. Journal of Food Science, 75:428 - 432.

Lee, H.S. and G.A. Coates, 2003. Effect of thermal pasteurization on Valencia orange juice color and pigments. LWT Food Sci Technol., 36: 153-156.

Luckow, T. and C. Delahunty, 2004. Which juice is healthier? A consumer study of probiotic non-dairy juice drinks. Food Qual Prefer., 15: 751- 759.

Majchrzak, D., B. Lahm, and K. Dürrschmid, 2010. Conventional and probiotic yogurts differ in sensory properties but not in consumers' preferences. Journal of Sensory Studies, 25: 431- 446.

Martins, E. M. F., A. M. Ramos, E. S. L. Vanzela, P. C. Stringheta, C. L. O. Pinto, and J. M. Martins, 2013. Products of vegetable origin: A new alternative for the consumption of probiotic bacteria. Food Research International, 51: 764- 770.

https://doi.org/10.1016/j.foodres.2013.01.047

Matusek, A., P. Meresz, T. K. D. Le, and F. Orsi, 2009. Effect of temperature and pH on the degradation of fructo-oligosaccharides. European Food Research and Technology, 228: 355365. https://doi.org/10.1007/s00217-008-0941-8

Miranda, R. F., M. M. de Paula, G. M. da Costa, C. E. Barão, A. C. R. da Silva, R. S. L. Raices, and T. C. Pimentel, 2019. Orange juice added with L. casei: Is there an impact of the probiotic addition methodology on the quality parameters? LWT, 106:186 - 193.

Mousavi, Z.E., S.M. Mousavi, S.H. Razavi, Z. Emam-Djomeh, and H. Kiani, 2011. Fermentation of pomegranate juice by probiotic lactic acid bacteria. World J Microbiol Biotechnol., 27(1):123-8.

Newgent, J., 2013. Prebiotics and Probiotics: The Dynamic Duo; Academy of .Nutrition and Dietetics: Chicago, IL, USA; $1-2$.

Oliveira, R.P.S., P. Perego, M.N. de Oliveira, and A. Converti, 2012. Effect of inulin on the growth and metabolism of a probiotic strain of Lactobacillus rhamnosus in co-culture with Streptococcus thermophilus. LWT - Food Science and Technology, 47, 358-363.

Önal Darilmaz, D., Ş. Sönmez, and Y. Beyatli, 2019. The effects of inulin as a prebiotic supplement and the synbiotic interactions of probiotics to improve oxalate degrading activity. International Journal of Food Science \& Technology, 54(1):121-131.

Osorio, C., D.P. Forero, and J.G. Carriazo, 2011. Characterisation and performance assessment of guava (Psidium guajava L.) microencapsulates obtained by spray-drying. Food Res Int 44: 1174-1181.

Ozden, A., 2008. Other fermented dairy products: bioyogurt-probiotic yogurt. Guncel Gastroenteroloji 12(3): 169-181.

Panghal, A., S. Janghu, K. Virkar, Y. Gat, V. Kumar, and N. Chhikara, 2018. Potential non-dairy probiotic products - A healthy approach. Food Bioscience, 21: 80- 89. https://doi.org/10.1016/j.fbio.2017.12.003

Penfield, M.P. and A. M. Campbell, 1990. Shortened Cakes. In "Experimental Food Science," 3rd ed. Academic Press, Inc. San Diego, CA. pp. 452-70.

Pereira, R.N., J.A. Teixeira, A. A. Vicente, P. Cappato, M. V. da Silva Ferreira, R. da Silva Rocha, and A. G. da Cruz, 2018. Osmic heating for the dairy industry: A potential technology to develop probiotic dairy foods in association with modifications of whey protein structure. Current Opinion in Food Science, 22: 95 - 101. 
Pimentel, T.C., G.S. Madrona, S. Garcia and S.H. Prudencio, 2015. Probiotic viability, physicochemical characteristics and acceptability during refrigerated storage of clarified apple juice supplemented with Lactobacillus paracasei ssp. paracasei and oligofructose in different package type. LWT Food Science and Technology of Food Industry, 63(1): 415-422.

Porto, M. R. A., V. S. Okina, T. C. Pimentel, S. Garcia, and S. H. Prudencio, 2018. Beet and orange mixed juices added with Lactobacillus acidophilus. Nutrition \& Food Science, 48(1): $76-87$.

Ranadheera, C.S., P.H.P. Prasanna, and J.K. Vidanarachchi, 2014. Fruit juice as probiotic carriers. In Fruit Juices: Types, Nutritional Composition and Health Benefits, 1st ed.; Elder, K.E., Ed.; Nova Science Publishers: Hauppauge, NY, USA, pp. 1-19.

Rezaei, R., M. Khomeiri, and M. Kashaninejad, 2012. Effect of inulin on the physicochemical properties, flow behavior and probiotic survival of frozen yogurt. Journal of Food Science and Technology 51: $2809-2814$.

Saad, N., C. Delattre, M. Urdaci, J.M. Schmitter, and P. Bressollier, 2013. An overview of the last advances in probiotic and prebiotic field. LWT-Food Sci Technol., 50: 1-16. https://doi.org/10.1016/j.lwt.2012.05.014

Shah, N and J.B. Prajapati, 2013. Effect of carbon dioxide on sensory attributes, physico-chemical parameters and viability of Probiotic L. helveticus MTCC 5463 in fermented milk. Journal of food Science and Technology 51 (12): 3886-3893.

SPSS, 1986. SPSS - Pc for the IBM PC / XT computer". Version 11.0 SPSS Inc., II. U.S.A.

Tarakci, Z. and E. Kucukoner, 2003. Physical, chemical, microbiological and sensory characteristics of some fruit-flavored yoghurt. YYÜ Vet Fak Derg, 14(2): 10- 14.

Thakur, M., 2016. Significance of prebiotics, probiotics and synbiotics as health potentiators. Food Science Research Journal, 7(2):327-334. https://doi.org/10.15740/HAS/FSRJ/7.2/327-334

Tomic, N., B. Dojnov, J. Miocinovic, I. Tomasevic, N. Smigic, I. Djekic, and Z. Vujcic, 2017. Enrichment of yoghurt with insoluble dietary fiber from triticale - A sensory perspective. LWT, 80: 59 - 66. https://doi.org/10.1016/j.lwt.2017.02.008

Tuohy, K.M., S. Kolida, A.M. Lustenberger, and G.R. Gibson, 2001. The probiotic effects of biscuits containing partially hydrolyzed guar and fructo-oligosaccharides - a human volunteer study. Br J Nutr. Sep; 86(3):341-8.

Verma, L. R. and V. K. Joshi, 2000. Postharvest technology of fruits and vegetables: Handling, processing, fermentation, and waste management. New Delhi, India: Indus Publishing Company.

Vieira, M. M. C. and C. L. Silva, 2014. Stability of cupuaçu (Theobroma grandiflorum) nectar during storage. International Journal of Food Studies, 3:160-174.

Vodnar, D. C., L. F. Călinoiu, L. Mitrea, G. Precup, M. Bindea, A. M. Păcurar, and B. E. Ştefănescu, 2019. A new generation of probiotic functional beverages using bioactive compounds from agroindustrial waste. In Functional and medicinal beverages (pp. 483- 528).Academic Press.

World Health Organization, 1963. International standards for drinking-water. 2nd ed., WHO, Geneva. 